\title{
Percepções conceituais sobre mediação da informação
}

\author{
Perceptions about mediation concept of information
}

\author{
Jonathas Luiz Carvalho Silva \\ Doutor em Ciência da Informação pela Universidade Federal da Bahia - UFBA. \\ Professor do Curso de Biblioteconomia da Universidade Federal do Cariri - UFCA. \\ E-mail: jonathascarvalhos@yahoo.com.br
}

\begin{abstract}
Resumo
Discute perspectivas conceituais de mediação da informação. $\mathrm{O}$ presente estudo tem como condição problematizadora uma questão a partir da seguinte pergunta: como é possível identificar e propor um conceito de mediação no campo da Ciência da Informação? O objetivo deste estudo é investigar os conceitos de mediação e mediação da informação a partir de um diálogo entre algumas áreas do conhecimento das ciências sociais, visando à proposição de um conceito de mediação no campo da Ciência da Informação. A metodologia do estudo é constituída de uma pesquisa bibliográfica mediante um diálogo com autores/textos diversos que abordam conceitualmente a mediação da informação. Conclui-se que o conceito de mediação no campo da Ciência da Informação ainda está em pleno desenvolvimento podendo se constituir como conjunto construtivo de práticas de intervenção e interferências tipificada por elementos técnicos, pedagógicos e institucionais.
\end{abstract}

Palavras-chave: Mediação da informação. Ciência da Informação. Mediação - técnica - pedagógica institucional.

\begin{abstract}
Discusses conceptual perspectives mediation of information. This study is problematical condition a question from the following question: how is it possible to identify and propose a concept of mediation in the field of information science? The objective of this study is to investigate the mediation and information mediation of concepts from a dialogue between some areas of social science knowledge, in order to propose a concept of mediation in the field of Information Science. The methodology of the study consists of a literature search through dialogue with authors / various texts that conceptually address the mediation of information. It follows that the concept of mediation in the field of information science is still in full development and it can act as constructive set of practices of intervention and interference typified by technical, pedagogical and institutional elements.
\end{abstract}

Keywords: Mediation of information. Information Science. Mediation - Technical - pedagogical - institutional.

InCID: R. Ci. Inf. e Doc., Ribeirão Preto, v. 6, n. 1, p. 93-108, mar./ago. 2015.

DOI: 10.11606/issn.2178-2075.v6i1p93-108 
Percepções conceituais sobre mediação da informação

\section{Introdução}

Os estudos e reflexões sobre mediação da informação vêm se estabelecendo em várias áreas do conhecimento e aplicados em vários segmentos profissionais. Isso ocorre pelo caráter múltiplo, plural e coletivo que a mediação possui, enquanto conceito, fundamento teórico, epistemológico e pragmático.

Uma das áreas em que a mediação vem se consolidado é a Ciência da Informação. Pode-se, inclusive, afirmar que a mediação da informação vem se constituindo como um dos primados básicos da Ciência da Informação que dialoga com várias áreas do conhecimento, principalmente a Comunicação e a Educação para desenvolver investigações sobre mediação da informação.

Todavia, embora a mediação seja um conceito trabalhado na Ciência da Informação, especialmente em fins do século XX e início do século XXI compreende-se que a mediação na Ciência da Informação ainda se configura como conceito embrionário e premente de uma construção de sentidos mais sólida.

A mediação da informação demonstra um caráter eminentemente plural dado o amplo diálogo científico, acadêmico e profissional estabelecido entre as diversas áreas do conhecimento que interferem na realidade acadêmica do ensino, extensão e, principalmente, da pesquisa, da pós-graduação e das associações científicas (elaboração de projetos, produção de artigos para eventos e periódicos, realização de eventos, parcerias internacionais, etc.), o que efetiva um processo, conforme afirma Couzinet (2000) chamado de mediação híbrida.

O presente estudo tem como condição problematizadora uma questão a partir da seguinte pergunta: como é possível identificar e propor um conceito de mediação no campo da Ciência da Informação? O objetivo deste estudo é investigar os conceitos de mediação e mediação da informação a partir de um diálogo entre algumas áreas do conhecimento das ciências sociais, visando à proposição de um conceito de mediação no campo da Ciência da Informação. 
Jonathas Luiz Carvalho Silva

\section{A mediação como construto de conhecimento e fundamento necessário na 'pós- modernidade'}

Os conceitos de mediação têm sido amplamente discutidos nas áreas do conhecimento, a partir de diferentes, semelhantes e complementares acepções, especialmente no período que compreende a chamada pós-modernidade.

Mas o que significa o termo pós-modernidade? Segundo Lyotard (1998, p. 15) "a pósmodernidade designa o estado de cultura após as transformações que afetaram as regras dos jogos da ciência, da literatura e das artes a partir do final do século XIX.” Já Eagleton (1998) afirma que a pós-modernidade é composta por um fenômeno histórico peculiar, que questiona as noções clássicas da verdade, da razão, da identidade e da objetividade, das ideias relacionadas ao progresso e das teorias constatadas como absolutas ou verdadeiras.

Nos conceitos apresentados pode-se perceber duas concepções, de certo modo, complementares: no primeiro conceito a pós-modernidade é vista como um conjunto de transformações culturais no âmbito da ciência, literatura e arte, enquanto no segundo conceito a pós-modernidade é vista como a transformação e questionamento dos valores como a verdade, razão, identidade, etc.

A noção de complementaridade entre os conceitos reside no fato de que o segundo conceito está contido no primeiro, já que questionar os valores demanda uma intrínseca relação com os fatores científicos, literários e artísticos.

Há um ponto, em caráter particular, que os conceitos convergem: ambos contemplam a percepção de mudança/transformação/transição de fenômenos culturais e valorativos da humanidade, o que implica pensar que a pós-modernidade se constitui a partir das mudanças dos valores firmados ad infinitum na sociedade contemporânea.

Todavia, é preciso pensar que o advento de uma 'pós-modernidade não significa necessariamente o fim ou uma ruptura com a modernidade, mas uma crise na própria modernidade que passa por mudanças constantes, intensas. ${ }^{1}$

\footnotetext{
${ }^{1}$ A discussão sobre modernidade e pós-modernidade possui um conjunto múltiplo, paradoxal e contraditório de concepções. O sociólogo polonês Zygmunt Bauman (2001) converge com a percepção de uma crise na modernidade quando indica que é dividida em dois contextos: a modernidade sólida, que pode ser considerado o período representado pela certeza, pela organização fabril baseadas nas ideias de Taylor, pela racionalidade instrumental, por empregos duradouros, por uma concepção territorial de espaço, economia, identidade e política e a modernidade líquida que é representada pela incerteza, pelas formas flexíveis de trabalho e organização, pela

InCID: R. Ci. Inf. e Doc., Ribeirão Preto, v. 6, n. 1, p. 93-108, mar./ago. 2015.
} 
Percepções conceituais sobre mediação da informação

Pensando a pós-modernidade como uma crise na modernidade e a constituição de um fundamento histórico, especialmente a partir do niilismo de Nietzsche e Heidegger é pertinente considerar que a história pode ser analisada como uma apropriação progressiva dos fundamentos racionais do conhecimento. Ora, se a história pode ser identificada como apropriação progressiva de conhecimento, seria necessário desvincular a noção de superação crítica do iluminismo, assim como considerar que a pós-modernidade não seria uma superação da modernidade, mas a revelação de valores e fundamentos do conhecimento que estavam subjacentes nas teorias iluministas. Em outras palavras, não há, de fato, uma superação da modernidade, mas um auto-entendimento da concepção de modernidade. (GIDDENS, 1991).

Diante dessa reflexão quais seriam as conseqüências da modernidade/pósmodernidade para a sociedade global? Inicialmente, é preciso considerar que o desiderato de mudança na modernidade/pós-modernidade está associado a um conjunto de valores que estão associados conforme afirma Morin (1994) a um processo de complexidade, subjetividade e instabilidade na sociedade.

Essa mudança de valores associadas à noção de complexidade, subjetividade e instabilidade está intrinsecamente ligada aos ideários de incerteza e insegurança (as comumente chamadas de era da incerteza/insegurança) na sociedade, o que se configura como uma das principais conseqüências da pós-modernidade.

A concepção de incerteza e insegurança é tão latente que no discurso de Lampert (2005) não é sabido se esse fenômeno representa um novo período de civilização: se é realmente uma mudança de paradigma, um movimento sócio-cultural ou simplesmente a reavaliação das posições críticas das teorias do pensamento moderno, já que avalia condições dicotômicas muito fechadas e rígidas criadas pela modernidade, tais como: objetividade/subjetividade; fato/imaginação; público/privado, dentre outras questões.

Nesse momento de incerteza e insegurança que é propalado em fins do século XIX e séculos XX e XXI, urge a necessidade de se pensar instrumentos que valorizem a consistência do pensamento humano e a construção de conhecimento. Um desses instrumentos é a mediação que tem sido largamente estudada nas áreas do conhecimento, especialmente na

guerra de informações, pela desterritorialização da política e da economia (globalização) e, sobretudo, pelo processo de individualização.

InCID: R. Ci. Inf. e Doc., Ribeirão Preto, v. 6, n. 1, p. 93-108, mar./ago. 2015. 
Jonathas Luiz Carvalho Silva

chamada pós-modernidade com a finalidade de lidar com os problemas da incerteza e da insegurança, estimular a construção e a socialização do conhecimento.

Observa-se o conceito de mediação fortemente atrelado às áreas do Direito, da Comunicação e da Educação. Acredita-se que o conceito de mediação se desenvolve a partir de algumas correntes teóricas e sociais do pensamento humano para construção do conhecimento, a saber:

a) o positivismo - a partir de uma visão lógico-formal das ações de mediação priorizando as concepções factuais e relegando a um plano inferior os processos históricos;

b) funcionalismo e teoria sistêmica - a função no sentido da satisfação de necessidades determinadas por demandas culturais (MALINOWSKI, 1977) e o sistema no âmbito de um conjunto de elementos em interação (BERTALANFFY, 1977);

c) teoria crítica - fundamento marxista que envolve a aplicação de métodos de investigação, visando erradicar diversas formas de dominação e estimular a formação de uma consciência e razão crítica e coletiva da sociedade;

d) sócio-interacionismo - contempla alguns princípios como igualdade (acesso à informação e ao conhecimento), reconhecimento das diferenças (reconhecimento da maturidade social, cultural e cognitiva de cada sujeito), inclusão (acesso à informação e ao conhecimento atentando para as necessidades de cada sujeito) e integralidade (busca romper com os processos de padronização, fragmentação do conhecimento) e autonomia (estimula o sujeito à reflexão, ao debate, à tomada de decisão de acordo com interesses, necessidades e motivações próprias, sem, no entanto, compartilhar de uma lógica de referência individualista). (RECIFE, 2002).

Desse modo iniciando pelo conceito de mediação no Direito o argumento de Sousa (2005) é salutar quando afirma que a mediação é o método consensual de solução de conflitos, que visa a facilitação do diálogo entre as partes, para que melhor administrem seus problemas e consigam, por si só, alcançar uma solução.

Observa-se que no Direito a mediação tem um significado categórico de resolver conflitos nos mais diversos setores (relações familiares, profissionais, humanas, etc.). Com efeito, o conflito não deve ser visto necessariamente como um problema insuperável ou eminentemente desgastante, mas também como uma oportunidade de crescimento pessoal, profissional, social e intelectual dos seres envolvidos. A mediação se configura precisamente 
Percepções conceituais sobre mediação da informação

com o instrumento de estímulo no aprimoramento das relações, o desenvolvimento de um diálogo mais franco, aberto e coletivo.

É muito comum o uso da mediação no Direito contemplando o ideário positivista. Todavia, essa mediação positiva do jurídico tem sido considerada como obsoleta, pelo menos no discurso, atentando para uma mediação mais crítica entre as partes, de modo que ambas possam ter voz e vez relegando a um plano inferior os processos de dominação de gênero, etnia, entre outros.

Já na Comunicação a mediação se estabelece como um novo ponto de origem e mais recente, de sorte que está vinculado ao sentido da mediação cultural, principalmente em algumas universidades francesas combinando vieses de disciplinas diversas, como a psicologia, sociologia e linguística. (CORROY; GONNET, 2008, p. 206).

Entende-se que a mediação cultural se estabelece como fenômeno eminentemente multidisciplinar, dado suas associações disciplinares, principalmente na psicologia (comportamento dos indivíduos), sociologia (processos de relações sociais) e lingüística (representação e significação da linguagem utilizada no processo de mediação cultural).

Logo, a mediação cultural pode ser entendida como uma construção e representação dos processos sociais e artísticos que busca no diálogo com indivíduos e/ou grupos promover significados e sentido a realidade humana a partir de um conjunto de atividades pensadas e constituídas coletiva e dialogicamente.

Lamizet (1999, p.9) aprofunda o conceito de mediação [cultural] quando nos revela que:

A mediação representa o imperativo social essencial da dialética entre o singular e o coletivo, e da sua representação em formas simbólicas. A sociedade pode existir apenas se cada um dos seus membros tem consciência de uma relação dialética necessária entre a sua própria existência e a existência da comunidade: é o sentido da mediação que constitui as formas culturais de pertença e de sociabilidade dandolhes uma linguagem e dando-lhes as formas e os usos pelos quais os atores da sociabilidade apropriam-se dos objetos constitutivos da cultura que funda simbolicamente as estruturas políticas e institucionais do contrato social. (...) É no espaço público que são levadas a efeito as formas da mediação, que trata-se do lugar no qual é possível tal dialetização das formas coletivas e as representações singulares. O espaço público é, por definição o lugar da mediação cultural

Podem-se apreender algumas percepções a partir do conceito de mediação cultural apresentado:

InCID: R. Ci. Inf. e Doc., Ribeirão Preto, v. 6, n. 1, p. 93-108, mar./ago. 2015. 
Jonathas Luiz Carvalho Silva

a) a mediação [cultural] está amplamente ligada às construções tensionadas e contraditórias (singular/coletivo) da sociedade por meio de representações simbólicas e no desiderato das concepções dialéticas;

b) a mediação subsidia a construção de procedimentos de pertencimento e identidade culturais que, a partir do jogo de linguagem, possibilita o uso e a apropriação dos elementos constitutivos da cultura e a formação de uma estrutura político-institucional (no sentido de formalizar as relações sociais através de projetos, parcerias institucionais entre o público e o privado, entre indivíduos e empresas, etc.);

c) mediação é concebida no espaço público que define as possibilidades territoriais e históricas para o desenvolvimento das representações simbólicas, políticas e institucionais da cultura, sendo preciso identificar o espaço público como instrumentos que permitem a dialetização das formas coletivas e representações singulares.

Já a mediação na Educação, ou mais precisamente na Psicologia da Educação e metodológica educacional, é resultante de um lato construto discursivo constituído a partir de correntes teóricas e estudiosos, tais como: construtivismo (PIAGET; GARCIA, 1987), a teoria sócio-histórica/sócio-interacionista (VYGOTSKY, 1998) e a mediatização (FREIRE 1987).

A mediação na Educação possui relação muito íntima com as questões sociais e psicológicas. Promovendo ênfase ao conceito de mediação, em Vygotsky, atenta-se para uma grande relevância deste conceito no que toca a idealização das funções psicológicas superiores (inserido na teoria sócio-histórica comumente chamada de teoria sóciointeracionista). Ao falar sobre mediação Vygotsky (1998, p. 73) revela que:

(...) O uso de meios artificiais - a transição para a atividade mediada - muda, fundamentalmente, todas as operações psicológicas, assim como o uso de instrumentos amplia de forma ilimitada a gama de atividades em cujo interior as novas funções psicológicas podem operar. Nesse contexto, podemos usar o termo função psicológica superior, ou comportamento superior com referência à combinação entre o instrumento e o signo na atividade psicológica.

Vygostky reconhece que a mediação interfere ou modifica as operações psicológicas ampliando e amadurecendo as atividades históricas, culturais, sociais e psicológicas do ser, o que implica dizer que a combinação entre o instrumento mediado e o resultado promovido na atividade psicológica do ser concebe uma função psicológica superior ou comportamento superior. 
Percepções conceituais sobre mediação da informação

Em suma, a mediação na teoria sócio-histórica/sócio-interacionista de Vygostsky contribui nos processos de apropriação e aprendizagem do ser por meio das interações e internalizações. A mediação possui um sentido de intervenção que liga o método da práxis a zona de desenvolvimento proximal (ZDP).

Finalmente, pondera-se a relevância da mediação para construção do conhecimento, de sorte que se configura como elemento histórico e social de ligação, intervenção, interferência, solução de conflitos, transformação, interação tão necessária em áreas do conhecimento [e mais amplamente na sociedade], visando auxiliar em uma realidade comumente enviesada por uma modernidade/pós-modernidade fragmentada e passível de incertezas e inseguranças.

\section{A mediação no âmbito da Ciência da Informação: percepções conceituais}

Assim como nas áreas do conhecimento mencionadas na seção anterior (Direito, Comunicação, Educação), a mediação vem sendo enfaticamente estudada na Ciência da Informação. Todavia, é notável uma deliberada importação dos conceitos de mediação pela Ciência da Informação.

Por isso, é pertinente um olhar cauto sobre o conceito de mediação cultural, de modo que promove as bases para pensar o conceito de mediação na Ciência da informação, ou melhor dizendo, a própria Ciência da Informação se apropria do conceito de mediação cultural aplicando em seus estudos e reflexões.

Malheiro e Ribeiro (2011, p. 153) afirmam que "não admira, de fato, que na Biblioteconomia e na Ciência da Informação ocorra uma importação simples e directa." Essa importação é bastante visível nas obras e dicionários de autores, como Cacaly (1997); MartinBarbero (2003); Lopes Yepes (2004); Faria e Pericão (2008).

Desse modo, os estudiosos sugerem a necessidade de se pensar uma apropriação crítica do conceito de mediação, visando fomentar de forma mais sólida o debate epistemológico sobre mediação. E como conceber uma concepção analítica acerca do conceito de mediação na Ciência da Informação? Inicialmente, pode-se pensar o conceito de mediação a partir de três fatores:

a) a mediação da informação não é um recorte de tempo estático, ela resulta da relação dos sujeitos com o mundo. (ALMEIDA JÚNIOR, 2008; 2009);

InCID: R. Ci. Inf. e Doc., Ribeirão Preto, v. 6, n. 1, p. 93-108, mar./ago. 2015. 
Jonathas Luiz Carvalho Silva

b) essa relação perpassa pelo processo de construção do conhecimento no qual os sujeitos interagem entre si e com as informações, processando-as para a partir de suas possibilidades cognitivas, se apropriarem do conteúdo quando ao final do processo um novo conhecimento é gerado e comunicado. (GOMES, 2008);

c) a mediação da informação é uma linha de pesquisa e fundamento de prática profissional que propõe atividades de interferência que vão além da relação usuário/informação. (SANCHES; RIO, 2010).

Apresentam-se três pontos centrais que norteiam o conceito de mediação na Ciência da Informação: o caráter dinâmico e relacional; construção de conhecimento a partir da interação entre os indivíduos; e linha de investigação referente à interferência promovida pela prática mediacional.

Pensar um conceito de mediação da informação demanda identificar o significado de informação tratado para associá-lo a mediação. Almeida Júnior (2009, p. 97) nos revela que a informação "está sendo empregada como criadora de conflitos, pois só estes viabilizam a transformação do conhecimento. A informação não dirime as dúvidas ou elimina incertezas. Ela exige a reconstrução do conhecimento na medida em que destrói certezas."

Este conceito de informação nos permite observar que a incerteza não é um fenômeno negativo, mas uma oportunidade para composição de novos questionamentos, novas ideias e aplicações, promovendo a reconstrução do conhecimento com a finalidade de atender necessidades singulares e coletivas.

Diante de uma informação articuladora, criadora de conflitos e que corrobora para a transformação social e construção do conhecimento, aborda-se o conceito de mediação na Ciência da Informação a partir de alguns contextos, sendo necessários discuti-los de forma particularizada a fim de posteriormente concatená-los, visando à estruturação prévia de um conceito.

O primeiro ponto é concernente a mediação da informação enquanto construto social. É evidente que a mediação não é neutra, de sorte que a medida que busca um diálogo com o usuário está construindo, se posicionando e mostrando alternativas. Desse modo, a mediação da informação pode ser afirmada em três palavras com grande intensidade de sentido: construção, intervenção e interferência.

InCID: R. Ci. Inf. e Doc., Ribeirão Preto, v. 6, n. 1, p. 93-108, mar./ago. 2015. 
Percepções conceituais sobre mediação da informação

A palavra construção é cabível em virtude de que todo o processo de mediação é construído socialmente, tanto pelas ações implícitas e explícitas envolvidas no processo de mediação quanto pelo incentivo ao posicionamento do usuário a partir de condições perspectivo-construtivas de uma autonomia da informação. Em outras palavras, é preciso que a mediação seja pensada em um plano paradigmático que seja socialmente construído de forma multilateral e dialógica concebendo interações entre mediadores e usuários estimulando a afirmação de suas percepções e desejos.

O processo de construção social da mediação se inicia em um contexto eminentemente prático, mais precisamente a partir das relações materiais e sociais. A mediação a partir das relações sociais auxilia na construção da consciência do indivíduo permitindo questionar certezas e reconstruir conhecimentos. O viés prático da mediação pode ser constatado em Marx (1983, p. 233-234) quando reitera que "não é a consciência dos homens que determina seu ser, mas, pelo contrário, o seu ser social que determina a sua consciência."

Logo, a mediação da informação é um construto que parte dos 'seres sociais' (relações múltiplas, plurais e coletivas entre os seres) e se consolida na formação da consciência do ser (passível de singularidade interpretativa de cada ser). De outro modo, a mediação é um construto social que se estabelece entre o ser e o mundo aproximando a teoria (conhecimento) da prática (ação), sendo que a construção de conhecimento deve ser composta a partir do real ou concreto (das configurações sociais, materiais e históricas), com vistas a transformação da realidade do(s) ser(es).

O segundo ponto da mediação da informação reside no argumento de Gomes (2010, p. 87) quando afirma que "para tratar de mediação, de início, é preciso situá-la como ação vinculada à vida, ao movimento, ao processo de construção de sentidos."

Como a informação preconizada é aquela que questiona certezas, modifica pensamentos e reconstrói conhecimento, a mediação da informação precisa ser vislumbrada a partir de uma perspectiva de construção de sentidos entre mediador e usuário; centro de informação e usuário; centro de informação e mediador; centro de informação, mediador e usuário.

A construção de sentidos é condicionante sine qua non no âmbito do movimento e da vida cotidiana dos seres envolvidos no processo de mediação. O movimento só é possível de forma dialógica e producente se está intrinsecamente concatenado ao cotidiano do usuário,

InCID: R. Ci. Inf. e Doc., Ribeirão Preto, v. 6, n. 1, p. 93-108, mar./ago. 2015. 
Jonathas Luiz Carvalho Silva

pois o cotidiano revela questões/situações que possibilitam o desenvolvimento de serviços que satisfaçam suas necessidades.

O terceiro ponto reside no argumento de Almeida Júnior (2009, p.92) quando afirma que a mediação "é toda ação de interferência - realizada pelo profissional da informação -, direta ou indireta; consciente ou inconsciente; singular ou plural; individual ou coletiva; que propicia a apropriação de informação que satisfaça, plena ou parcialmente, uma necessidade informacional."

Neste aspecto, a mediação da informação passa a ser protagonista no âmbito da Ciência da Informação, pois reflete uma fundamentação social mais consistente de investigação e prática social envidada pelo profissional da informação.

A fundamentação social da mediação da informação está vinculada aos processos dialógicos, interacionistas, desvinculados de hierarquias e procedimentos muito burocráticos, mas na perspectiva de que todos os seres envolvidos no processo de mediação em centros de informação são interdependentes e necessitam de um olhar interacionista horizontal, buscando reconhecer as igualdades de oportunidades, diferenças e a autonomia dos seres envolvidos.

Assim, diante dos três pontos estabelecidos para discussão pode-se definir a mediação da informação como sendo:

- um conjunto de práticas construtivas de intervenções e interferências regidas por intencionalidades, normas/regras, correntes teórico-ideológicas e crenças concebidas pelo profissional da informação em interação com os usuários no âmbito de suas realidades cotidianas e experienciais, indicando procedimentos singulares, coletivos e/ou plurais de acesso e uso da informação, estimulando à apreensão e apropriação para satisfação de necessidades de informação;

- neste conceito, o uso dos termos 'conjunto de práticas construtivas' é referente a várias questões, tais como a mediação como ação contextualizada a partir da prática conduzida mediante percepção sobre a realidade objetiva dos usuários, a consideração das múltiplas realidades dos usuários envolvidos que devem interagir entre si, assim como agir como protagonistas nos processos de produção da informação;

- já o uso dos termos intervenções e interferências se estabelecem de forma complementar, uma vez que o primeiro significa a prática da mediação propriamente

InCID: R. Ci. Inf. e Doc., Ribeirão Preto, v. 6, n. 1, p. 93-108, mar./ago. 2015. 
Percepções conceituais sobre mediação da informação

dita com a finalidade de mudança de um estado para outro por meio dos recursos, fontes e serviços de informação (neste caso, a intervenção significa uma tentativa de mudança prioritária do estado do usuário e também do próprio profissional da informação e do centro de informação) e a interferência seria a transformação social e cognitiva concebida a partir da intervenção, em caráter particular, do usuário, de sorte que a intervenção tem um constituinte inicial fundante de relacionar a tríade centro de informação-profissional da informação-usuário, enquanto a interferência busca promover reconstruções de conhecimento pelo usuário e uma reavaliação das práticas mediacionais envidadas pelo profissional da informação;

- já a parte 'regidas por normas/regras, intencionalidades, correntes teórico-ideológicas e crenças' implica que as normas/regras são os aspectos estabelecidos institucionalmente e que devem ser cumpridos pelo profissional da informação e usuários; as intencionalidades concernem às maneiras como os sujeitos da informação (profissional e usuário da informação) foram orientados (ou se auto orientaram) para definir suas ações ou tomar decisões, conforme suas dinâmicas de origem, temporais e normativas; as correntes teórico-ideológicas designam a conduta prática de ação no âmbito, por exemplo, do positivismo, funcionalismo, teoria crítica, construtivismo e sócio-interacionismo e as crenças são valores possivelmente verídicos que os sujeitos da informação acreditam para mediar e produzir informação.

Contudo, o conceito de mediação da informação (e o próprio conceito de informação) atribuído a partir da concepção do paradigma social da Ciência da Informação (CAPURRO, 2003) demanda um olhar crítico, dialógico, interacionista e investigativo por parte do profissional da informação, de modo que qualquer ação envidada por um centro de informação (e evidentemente pelo profissional da informação) possui caráter coletivo e voltado para satisfação de necessidades de informação.

Isso significa dizer que a mediação da informação não deve ser aplicada somente para o usuário, mas também com o usuário (SILVA, 2012), de modo que a prática mediacional, em seus fundamentos de intervenção e interferência ocorra a partir de uma perspectiva de diálogo e ação recíproca, considerando as particularidades/necessidades de cada segmento participante do processo de mediação e as particularidades/necessidades do usuário.

Pode-se assim, identificar e explicitar alguns tipos de mediação passíveis de serem aplicados principalmente em centros de informação considerando que toda e qualquer 
Jonathas Luiz Carvalho Silva

mediação é um construto social, crítico e interacionista e envolve contextos coletivos e plurais:

a) mediação técnica da informação - concerne as ações de organização, representação da informação envidadas pelo profissional da informação estimulando o uso da informação, seja em ambiente físico ou virtual. Por exemplo, a elaboração de catálogos, interação por e-mail e/ou redes sociais do acervo do centro de informação, entre outros.

b) a mediação pedagógica da informação - consiste na condução dos procedimentos e heurísticas a serem utilizadas no processo de mediação. Para tanto, é fundamental um olhar constante nos estudos de usuários contemplando questões relativas ao uso do acervo, das condições tecnológicas, do serviço, das questões de pessoal e avaliação da atuação do centro de informação de forma geral buscando uma aproximação com a comunidade, assim como promovendo autonomia para que o usuário tenha condições de escolha para apreensão e apropriação da informação;

c) mediação institucional da informação - está relacionada aos procedimentos de como o profissional da informação irá buscar recursos (financeiros, pessoais, equipamentos, acervo, instrumentos tecnológicos, etc.), seja dentro ou fora da instituição que o centro de informação está inserido para concretizar suas ações e interferências, assim como promover sua sustentabilidade. $^{2}$

Observa-se, desse modo, que a mediação constitui um papel central nos estudos em Ciência da Informação, pois além de conferir novas aplicabilidades e percepções conceituais para este Campo, contribui de forma efetiva para pensar a atuação dos centros de informação, assim como está vinculada a fatores diversos da Ciência da informação, como aspectos teórico-epistemológicos, tecnologia, gestão, serviços, estudos de usuários, entre outros assuntos da área.

\footnotetext{
${ }^{2}$ A sustentabilidade está aqui focalizada como sendo a possibilidade do centro de informação justificar a necessidade de sua existência. Para tanto é preciso instituir nas ações do centro de informação o uso equilibrado de seus recursos financeiros, de pessoal, sem promover gastos financeiros demasiados e sem proceder grandes dispêndios financeiros à sua instituição, seja pública ou privada (Universidade, Escola, etc.), mas contemplando o ideário de que o centro de informação é um investimento e não simplesmente um gasto. Outrossim, é preciso alavancar parcerias com outras instituições (também públicas e/ou privadas), buscando os recursos (financeiros, estruturais...) necessários para as práticas mediacionais, o que permite pensar uma autonomia políticoinstitucional do centro de informação que pode contribuir para a implementação do processo de mediação.
}

InCID: R. Ci. Inf. e Doc., Ribeirão Preto, v. 6, n. 1, p. 93-108, mar./ago. 2015. 
Percepções conceituais sobre mediação da informação

\section{Considerações Finais}

O presente estudo mostrou algumas percepções relativas ao conceito de mediação em algumas áreas do conhecimento, como o Direito, a Comunicação e a Educação. Em caráter especial, o estudo desenvolveu uma reflexão teórico-conceitual sobre a mediação da informação e sua incidência na Ciência da Informação indicando percepções conceituais.

Entende-se que pelo caráter inesgotável das discussões sobre mediação da informação e suas contribuições para a Ciência da Informação, este estudo não deve estabelecer conclusões definitivas, mas indicar a possibilidade de novas discussões sobre a mediação da informação.

Considerando que a mediação da informação merece mais estudos de cunho conceitual e histórico, especialmente contemplando as investigações no campo da Ciência da Informação, além de estudos e aplicações profissionais no que toca a Biblioteconomia é necessário alavancar mais reflexões sobre a temática estimulando a apropriação de conceitos mais críticos em detrimento da simples importação de conceitos de outras áreas.

Observa-se a mediação da informação como um conceito denso e que envolve fatores diversos como o centro de informação, profissional da informação e usuários como uma tríade que demanda a necessidade de uma construção social e interacionista compreendendo a informação como fenômeno transformador, norteador de novas questões e estimulante na construção de novos conhecimentos.

Portanto, é pertinente reconhecer a mediação como uma construção social, crítica e deliberada da prática à teoria (a mediação da informação necessita ser pensada a partir das relações sociais, materiais e históricas à formação de uma consciência crítica). Para tanto, é condição sine qua non identificar os atributos técnicos, pedagógicos e institucionais da mediação nos centros de informação, visando promover consistência a prática da mediação como fenômeno que promove igualdade de oportunidades, reconhecimento das diferenças, integração, inclusão e autonomia.

InCID: R. Ci. Inf. e Doc., Ribeirão Preto, v. 6, n. 1, p. 93-108, mar./ago. 2015. 


\section{Referências}

ALMEIDA JÚNIOR, O. F. Mediação da informação e múltiplas linguagens. In: ENCONTRO NACIONAL DE PESQUISA EM CIÊNCIA DA INFORMAÇÃO, 9., 2008, São Paulo. Anais eletrônicos... São Paulo: ANCIB, 2008.

Mediação da informação e múltiplas linguagens. Tendências da pesquisa brasileira em Ciência da Informação, Brasília, v. 2, n. 1, p. 89-03, jan./dez. 2009.

BAUMAN, Z. Modernidade líquida. Rio de Janeiro: Jorge Zahar, 2001.

BERTALANFFY, L. V. Teoria geral dos sistemas. In: BIRNBAUM, P.; CHAZEL.

Teoria sociológica. São Paulo, HUCITEC-EDUSP, 1977.

CACALY, S. (Coord.). Dictionnaire encyclopédique de l'information et de la documentation. Paris: Nathan, 1997.

CAPURRO, R. Epistemologia e Ciência da Informação. In: ENCONTRO NACIONAL DE PESQUISA EM CIÊNCIA DA INFORMAÇÃO, 5., Belo Horizonte, 2003. Anais... Belo Horizonte: Escola de Ciência da Informação da UFMG, 2003.

CORROY, L.; GONNET, J. Médiation. In: DICTIONNAIRE d'initiation à l'info-com. 2ème édition. Paris: Magnard-Vuibert, 2008. p. 204-209.

COUZINET, V. Médiations hybrides: le documentaliste et le chercheur en Sciences de l'Information. Paris: ADBS, 2000.

EAGLETON, T. As ilusões do pós-modernismo. Rio de Janeiro: Jorge Zahar, 1998.

FARIA, M. I.; PERICÃO, M. G. Dicionário do livro: da escrita ao livro electrónico. Coimbra: Almedina, 2008.

FREIRE, P. Pedagogia do oprimido. 17 ed. Rio de Janeiro: Paz e Terra, 1987.

GIDDENS, A. As consequiências da modernidade. São Paulo: Ed. da UNESP, 1991.

GOMES, H. F. A mediação da informação, comunicação e educação na construção do conhecimento. Datagramazero, [Rio de Janeiro], v. 9, n. 1, fev. 2008. Disponível em: <http://dgz.org.br/fev08/F_I_art.htm>. Acesso em: 12 dez. 2011.

Tendências de pesquisa sobre mediação, circulação e apropriação da informação no Brasil: estudo em periódicos e anais dos ENANCIB (2008-2009). Pesquisa brasileira em Ciência da Informação, Brasília, v. 3, n. 1, p. 85-99, jan./dez. 2010.

LAMIZET, B. La médiation culturelle. Paris: L'Harmattan, 1999.

LAMPERT, E. Pós-modernidade e conhecimento: educação, sociedade, ambiente e comportamento humano. Porto Alegre: Sulina, 2005. 
Percepções conceituais sobre mediação da informação

LYOTARD, J-F. A condição pós-moderna. 5. ed. Rio de Janeiro: José Olympio, 1998.

LOPES YEPES, J. Diccionario enciclopédico de ciências de la documentación. Madrid: Sintesis, 2004.

MALHEIRO, A.; RIBEIRO, F. Paradigmas, serviços e mediações em Ciência da Informação. Recife: Néctar, 2011.

MALINOWSKI, B. A Teoria funcional. In: BIRNBAUM, P.; CHAZEL. Teoria sociológica. São Paulo, HUCITEC-EDUSP, 1977.

MARTÍN-BARBERO, J. Dos meios às mediações: comunicação, cultura e hegemonia. Rio de Janeiro: Ed. UFRJ, 2003.

MARX, K. Contribuição à crítica da economia política. São Paulo: Martins Fontes, 1983.

MORIN, E. Ciência com consciência. Lisboa: Europa-América, 1994.

PIAGET, J.; GARCIA, R. Psicogênese e história das ciências. Lisboa: Dom Quixote, 1987.

RECIFE. Prefeitura Municipal. Estudos intensivos/ciclos de aprendizagem e organização escolar, fev. 2002.

SANCHES, G. A. R.; RIO, S. F. Mediação da informação no fazer bibliotecário no âmbito das ações culturais. InCID: Revista de Ciência da Informação e Documentação, Ribeirão Preto, v. 1, n. 2, p. 103-121, jul./dez., 2010.

SILVA, J. L. C. Necessidades de informação e satisfação do usuário: algumas considerações no âmbito dos usuários da informação. InCID: Revista de Ciência da Informação e Documentação, Ribeirão Preto, v. 3, n. 2, p. 102-123, jul./dez. 2012. Disponível em: <http://www.revistas.usp.br/incid/article/view/48656/52727>. Acesso em: 21 jan. 2013.

SOUSA, L. A. A utilização da mediação de conflitos no processo judicial. Jus Navigandi, Teresina, ano 10, n. 568, 26 jan. 2005. Disponível em: <http://jus.com.br/revista/texto/6199>. Acesso em: 11 fev. 2012.

VYGOTSKY, L. S. A formação social da mente: o desenvolvimento dos processos psicológicos superiores. 6. ed. São Paulo: Martins Fontes, 1998. 